\title{
Industrial Revolution
}

Anne Porterfield, NC State University, USA

Keywords: Embroidery, engineered design, denim

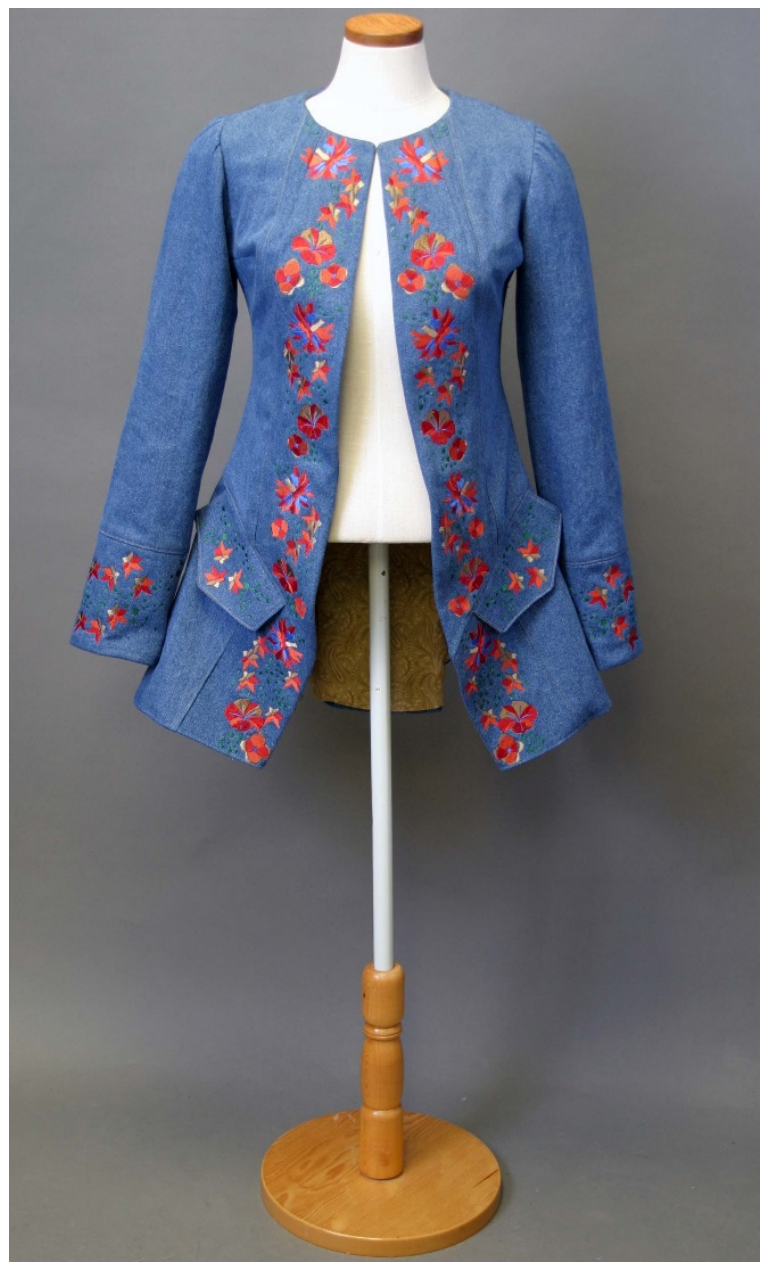

This woman's jacket combines a silhouette inspired by $18^{\text {th }}$ century menswear with the most ubiquitous of modern fabrics, denim. The fit and flare of men's coats from that period was easily translated into a woman's garment. The challenge in this project was to incorporate fabrics and surface design that would work in a modern context. After researching several approaches to embroidery on men's $18^{\text {th }}$ century coats, (Fukai et.al., 2002; Tozer and Levitt, 1989) I determined that rich primary colors could be used on a dark surface to create an effect true to the period. Using denim brought the design into the $21^{\text {st }}$ century, and the combination of denim and embroidery added a feel of the American Southwest. Embroidery motifs were created from drawings of local flowers in bloom at the time the garment was created, including columbine, morning glory, and vinca. In keeping with the western theme, flowers were reduced to simple silhouettes. Red, orange, and brown were used as the main colors, with blue and green as accents.

The process for creating this garment started with draping. Darts were necessary to make the jacket work on a female form. Additional shaping techniques were discovered in the online collection of the L.A. County Museum of Art where patterns for selected historic garments are available for review (LACMA, 2010). This led to the inclusion of a shaping dart under the pocket flap that helped to increase the flare of the center front.

Once the pattern was finalized, flower motifs were digitized and imported into Tajima DG/ML Pulse embroidery software. The front border was created by placing motifs over a scan of the front pattern. The embroidery was done on a TFMX-C1501 electronic multi-head automatic 
embroidery machine. Larger patterns were broken into smaller segments to accommodate the size limitations of the machine.

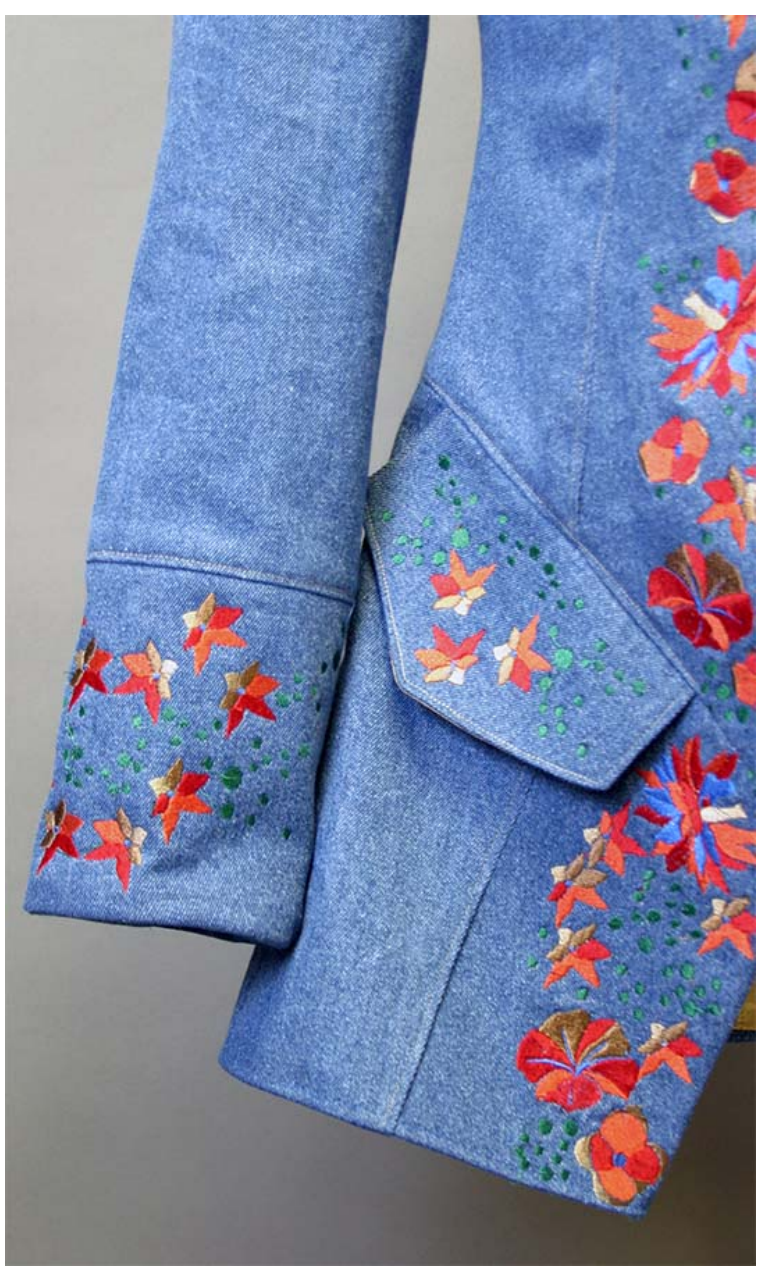

The engineering that went into this design harkens back to the beginning of the industrial revolution when machines were created to do detailed work that had previously been done by hand. The result is a jacket with the attitude and flair of an eighteenth century courtier, ready to be worn by a $21^{\text {st }}$ century gal.

Fukai, A., Souh, T., Iwagami, M., Koga, R., and Nii, Rie, (Eds.) (2002). Fashion : The collection of the Kyoto costume institute: A history from the 18th to the $20^{\text {th }}$ century. . Köln ; New York: Taschen. Retrieved from http://www2.lib.ncsu.edu/catalog/record/NCSU1602325

LACMA (2010). Patterns from our collection. http://www.lacma.org/patterns

Tozer, J. and Levitt, S. (Eds.). (1983). Fabric of society : A century of people and their clothes, 1770-1870 Manchester. Carno, Powys, Wales: L. Ashley. Retrieved from http://www2.lib.ncsu.edu/catalog/record/DUKE000612580 